\title{
David Oliver: Lessons from the Babylon Health saga
}

\author{
David Oliver consultant in geriatrics and acute general medicine
}

Berkshire

The long awaited evaluation of Babylon Health's GP at Hand service has been published. ${ }^{1}$ It found that patients had fewer health problems than conventional users of GP services, were younger, and yet were higher users of services such as NHS 111 and urgent care. ${ }^{2}$

The report noted that GP at Hand didn't provide the full range of services that conventional general practices do and that expanding such a model would have considerable implications for IT, infrastructure, and the GP workforce. But it could "not fully assess whether GP at Hand is affordable or sustainable."3

GP at Hand's presence in Hammersmith and Fulham Clinical Commissioning Group has reportedly faced big and growing costs (estimated at $£ 10 \mathrm{~m}$ so far) from hosting GP at Hand, which supports patients living in other parts of London-putting general practice delivery for local residents at greater risk. ${ }^{4}$

The saga of Babylon's entry to the NHS market raises some concerns we'd do well to learn from.

First, independent evaluation does matter. Babylon's medical director, Mobasher Butt, said on the record that randomised controlled trials and peer review aren't so suitable for such quickly and constantly evolving technology. ${ }^{5}$ True, perhaps, but other forms of pragmatic evaluation are available. The National Institute for Health and Care Excellence (NICE) has recently published guidance for evaluating new health tech, ${ }^{6}$ and NICE is a statutory body. Let's adopt these standards when it comes to spending scarce public resources on new health technology in a safety critical service. Evaluation must not centre simply on consumer experience and satisfaction but on the whole system impact and the risks, affordability, sustainability, and ability to scale up.

Second, we need legislation to ensure that private companies contracting with the NHS are sufficiently open to scrutiny and subject to same disclosure requirements as NHS organisations. Doctors outside Babylon have raised concerns online, saying that the advice given in response to symptoms they entered into the checker was misleading and potentially dangerous. ${ }^{78}$ I realise that AI programmes evolve and improve over time-but the marketing didn't say "work in progress."
Third, ministerial codes should ensure that no health secretary pushes and promotes individual companies with the enthusiasm Matt Hancock has shown. This has drawn formal complaint from the Labour Party about ministerial conduct. ${ }^{9}$ Hancock already has connections to think tanks that support marketisation of healthcare and a shrinking of the state, such as the Institute of Economic Affairs ${ }^{10}$ and the TaxPayers' Alliance. ${ }^{11}$ Remember that the Nolan principles for public life (still endorsed on the government's website) include impartiality and objectivity. ${ }^{12}$

Fourth, the impact and opportunity cost of any similar innovation on other service users needs careful consideration. The Babylon evaluation exemplified the inverse care law $^{13}$ at work, whereby youngish, educated urban professionals with low health needs were consuming a disproportionately high amount of scarce NHS resources. Perhaps they should have the option to pay for such concierge convenience, considering that GPs get an average of only $£ 151$ ( $€ 171 ; \$ 191)$ per patient on their list per year, however complex their needs. ${ }^{14}$

Fifth, infrastructure is vital, in terms of financial payment mechanisms and flows, affordability, and adequate workforce. This shouldn't be an afterthought in our enthusiasm to adopt new technology.

Sixth—and most importantly—we must clamp down hard on aggressive marketing. The Advertising Standards Authority has upheld complaints about Babylon's misleading adverts. ${ }^{15} 16$ Babylon has also claimed that its AI symptom checker could outperform human doctors at sitting the MRCGP exam, ${ }^{17}$ although the basis for this claim has been disputed by researchers. ${ }^{18}$

Babylon is now being rolled out to Birmingham (a decision made before the evaluation was published), amid enthusiastic claims about all the problems it will solve in urgent care. ${ }^{19}$ But it's just one of many disruptive technology innovators wanting to enter the NHS market. We need a far tighter code of practice so that objective evidence is clearly distinguished from promotional and marketing claims made by commercial organisations seeking to profit from it. 
1 Ipsos MORI. Evaluation of Babylon GP at Hand: final evaluation report. May 2019. https: //www.hammersmithfulhamccg.nhs.uk/media/156123/Evaluation-of-Babylon-GP-at-HandFinal-Report.pdf.

2 lacobucci G. GP at Hand: patients are less sick than others but use services more, evaluation finds. BMJ 2019;365:I2333. 10.1136/bmj.I2333 31126910

3 Ram A, Cundy A. Babylon's GP at Hand app raises questions over NHS tech tie-ups. Financial Times 2019 May 29. https://www.ft.com/content/b981c07c-7e0f-11e9-81d2f785092ab560.

4 Heather B. Service cut warning over NHSE's GP at Hand bailout fears. Health Serv $J$ 2019 Mar 12. https://www.hsj.co.uk/technology-and-innovation/service-cut-warning-overnhses-gp-at-hand-bailout-fears/7024604.article.

5 Burgess M, Kobie N. The messy, cautionary tale of how Babylon disrupted the NHS. Wired 2019 Mar 18. https://www.wired.co.uk/article/babylon-health-nhs.

6 National Institute for Health and Care Excellence. Medical technologies guidance. https: //www.nice.org.uk/about/what-we-do/our-programmes/nice-guidance/nice-medicaltechnologies-guidance.

7 Blanchard S. NHS-backed GP chatbot asks a 66-year-old woman if she's PREGNANT before failing to suggest a breast lump could be cancer. MailOnline $2019 \mathrm{Feb} 27$. https:/ /www.dailymail.co.uk/health/article-6751393/NHS-backed-GP-chatbot-branded-publichealth-danger.html.

8 Kay A. Doctor, doctor, I'm being diagnosed by robot and I've a bad feeling about it. Sunday Times 2019 Jan 13. https://www.thetimes.co.uk/article/doctor-doctor-im-being-diagnosedby-robot-and-ive-abad-feeling-about-it-gpff95fk9. (Login needed.)

9 Syal R. Matt Hancock accused of breaching code over GP app endorsement. Guardian 2018 Nov 30. https://www.theguardian.com/politics/2018/nov/30/matt-hancock-accusedof-breaching-code-over-gp-app-endorsement.

10 Matthews-King A. Anti-NHS think-tank with links to new health secretary Matt Hancock under investigation by charity commission. Independent $2018 \mathrm{Jul} 12$. https://www. independent.co.uk/news/health/nhs-think-tank-matt-hancock-institute-economic-affairsiea-health-secretary-a8443826.html.

11 Oliver D. David Oliver: The TaxPayers' Alliance, Hancock, and health technology. BM 2019;365:11918. 10.1136/bmj.I1918 31043376

12 Committee on Standards in Public Life. The 7 principles of public life. 31 May 1995. https: //www.gov.uk/government/publications/the-7-principles-of-public-life.

13 Appleby J, Deeming C. Inverse care law. King's Fund. 21 June 2001. https://www. kingsfund.org.uk/publications/articles/inverse-care-law.

14 Vautrey R. Dr Richard Vautrey: £151 per patient for unlimited care? No wonder GPs are struggling. GP2017 Sep 22. https://www.gponline.com/dr-richard-vautrey-151-per-patientunlimited-care-no-wonder-gps-struggling/article/1445459.

15 Bradley S. Digital health startup Babylon hit by ASA bans over "misleading" tube posters. The Drum 2018 Oct 3. https://www.thedrum.com/news/2018/10/03/digital-health-startupbabylon-hit-asa-bans-over-misleading-tube-posters.

16 Advertising Standards Authority. ASA ruling on Babylon Healthcare Services Ltd t/a GP at Hand. 3 Oct 2018. https://www.asa.org.uk/rulings/babylon-healthcare-services-Itd-a18439274.html.

17 Copestake J. Babylon claims its chatbot beats GPs at medical exam. BBC News 2018 Jun 27. https://www.bbc.co.uk/news/technology-44635134.

18 Postelnicu L. Researchers question Babylon claims that its system beat doctors at RCGP exam. Mobi Health News 2018 Nov 7. https://www.mobihealthnews.com/content/ researchers-question-babylon-claims-its-system-beat-doctors-rcgp-exam.

19 Mahase E. Birmingham trust and Babylon Health discuss pre-A\&E triage app. BMJ 2019;365:I2354. https://www.bmj.com/content/365/bmj.I2354. 10.1136/bmj.12354 31138534 Published by the BMJ Publishing Group Limited. For permission to use (where not already granted under a licence) please go to http://group.bmj.com/group/rights-licensing/ permissions 